\title{
Evaluation of Insulin Use and Value for Money in Type 2 Diabetes in the United Kingdom
}

\author{
Jason Gordon • Marc Evans • Phil McEwan • \\ Steve Bain $\cdot$ Jiten Vora
}

To view enhanced content go to www.diabetestherapy-open.com

Received: September 27, 2012 / Published online: January 8, 2013

(c) The Author(s) 2013. This article is published with open access at Springerlink.com

\begin{abstract}
Introduction: It is unclear as to whether human or long-acting analog insulins
\end{abstract}

J. Gordon $(\bowtie)$

Department of Public Health,

University of Adelaide, Level 7, 178 North Terrace, Adelaide, SA 5005, Australia

e-mail: jason.gordon@adelaide.edu.au

J. Gordon

HEOR Consulting Pty Ltd, Adelaide, SA, Australia

M. Evans

Department of General Medicine, Diabetes and Endocrinology, Cardiff University Local Health Board, University Hospital Llandough, Llandough, UK

\section{P. McEwan}

HEOR Consulting Ltd, Singleton Court Business Park, Wonastow Rd, Monmouth, UK

S. Bain

Singleton Hospital, Sketty Lane, Swansea, UK

J. Vora

Royal Liverpool University Hospital, Link 7C, Prescot Street, Liverpool L7 8XP, UK

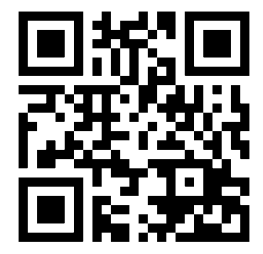

Enhanced content for this article is

available on the journal web site:

www.diabetestherapy-open.com represent the most efficient use of health and non-healthcare resources in the management of type 2 diabetes mellitus (T2DM). The aim of this study was to evaluate the value for money relationship associated with the use of these insulins in the UK setting.

Methods: A literature search was performed for studies reporting expenditure associated with the use of human and analog insulins. Data from this review informed a budget impact assessment model. Costs were converted to a common currency and results are reported in 2011 British pounds sterling (GBP) values.

Results: Annual diabetes-related medication expenditure and patients total expenditure associated with the management of T2DM were estimated to be $£ 397$ million and $£ 3,901$ million, respectively. Substitution of human insulin for analog insulins was associated with a drug acquisition cost saving of between $£ 5$ million and $£ 23$ million each year. Overall, though, total expenditure increased significantly with increased use of human insulin by $£ 34$ million to $£ 136$ million each year depending on the degree of substitution.

Conclusions: On the face of it, analog insulins are more expensive, prompting questions about potential cost savings to health services in the UK from direct substitution to the less 
expensive human preparation. The current analysis illustrates that the increased use of human insulin and decreased use of analog insulin would, however, increase the overall net societal cost of managing insulin-treated patients with T2DM. Governments and decision makers should consider that total healthcare expenditure would not necessarily fall when decisions are based solely on the use of cheaper products.

Keywords: Costs and cost analysis; Diabetes mellitus; Human insulin; Insulin analog; Resource allocation; Type 2 diabetes

\section{INTRODUCTION}

\section{Background}

There are an estimated 346 million people with diabetes worldwide. Type 2 diabetes mellitus (T2DM) is the most common, accounting for $90 \%$ of the diabetic population [1]. Unlike people with type 1 diabetes, who require insulin, people with T2DM can initially manage their condition without pharmacological intervention. However, the natural history of T2DM, characterized by progressive decline in beta cell function, results in an inevitable need for multiple pharmacotherapies including oral antidiabetic drugs (OADs), insulin, or both, in order to optimize blood glucose control [2]. Indeed, over the course of the UK Prospective Diabetes Study (UKPDS), $>50 \%$ people treated with sulfonylureas required additional insulin to maintain fasting plasma glucose levels $<6 \mathrm{mmol} / \mathrm{L}$, within 6 years of T2DM diagnosis [3].

There is a growing emphasis on insulin management. Insulin initiation early within the natural history of T2DM is now endorsed by professional bodies including the American Diabetes Association (ADA) and the European
Association for the Study of Diabetes (EASD) [4]. The growing prevalence of T2DM and data suggesting a reduction in mortality in people with T2DM indicate that the use of insulin for the management of glucose control in people with T2DM will continue to rise [5].

Accordingly, there is widespread interest in evaluating the safety, efficacy, costeffectiveness, and affordability of alternative insulin treatments. A number of insulin products are available that address variability in patient phenotypes, preference, and response to treatment. Preparations are available that more closely mimic normal insulin production (short-acting) or provide a continuous supply of insulin over a longer time period (intermediateand long-acting).

\section{Recent Evidence}

The intermediate-acting human isophane insulin (NPH) and the long-acting analog insulins glargine and detemir have been the subject of recent reviews that have brought into question the clinical benefits and economic value of long-acting insulin analogs compared to human insulin [6-8]. These reviews suggest that insulin analogs and NPH are similarly effective in terms of glycemic control; however, clinical and economic value should also be assessed from the perspective of other clinical endpoints, including hypoglycemia [9]. Hypoglycemia is a recognized consequence of intensification of glucose control [10-12]. In people with T2DM receiving insulin therapy for $<2$ years, nearly $50 \%$ of patients reported recurrent symptomatic hypoglycemia, while $20 \%$ of patients reported at least one episode of severe hypoglycemia [13]. Hypoglycemia has significant clinical and economic implications, thus an increase in the rate of hypoglycemia with human compared to analog insulin may 
exert significant health economic implications [14-17]. Further, it is important to remember that these reviews were based on the results of randomized controlled trials that evaluated highly selected patient populations under tightly controlled conditions [6, 7]. As such, these conclusions may not truly reflect patient outcomes as observed in clinical practice nor reflect the actual value of human insulin compared to analog insulin.

Nonetheless, a natural question arising from these reviews is whether health systems could achieve productivity savings from switching to human insulin. A recent analysis characterizing patterns of insulin prescriptions suggested that the UK National Health Service (NHS) would have achieved savings of $£ 635$ million from 2000 to 2009, had all prescriptions been for human insulin [8]. Thus, on the face of it, starting people with T2DM on human insulin or even converting people from analog insulin may reduce health expenditure. However, there are other relevant considerations when informing decisions around the optimization of health spending and medication choice in the treatment of T2DM.

\section{Acquisition Costs and Total Expenditure}

A comparison of product acquisition costs alone, that is the cost of prescribed medications to the NHS, fails to address the much larger set of costs associated with the management of T2DM. The other parameters that should be considered in a value for money evaluation include both direct and indirect costs. The direct costs for diabetes patients include publicly funded healthcare, most often in terms of primary and secondary care, prescribed medications, and other treatments. The indirect costs incurred by patients, their families, and caregivers include time spent in managing the symptoms of T2DM and adjusting their lifestyles to the needs of the condition; for example, they incur out-ofpocket expenses associated with transport to healthcare services and in paying for specialist foods used to regulate metabolic activity. When the full spectrum of cost is considered, then medication costs, OADs, and insulin account for only $7 \%$ of total healthcare expenditure in the management of T2DM, while diabetesrelated late complications and hospitalizations are the single greatest determinant of costs [18]. Hence, from the perspective of informing public spending decisions, an evaluation of acquisition costs alone does not provide a true sense of the total economic consequences associated with insulin choice.

\section{Aims}

The purpose of this study was to extend the analysis of human versus analog basal insulin to illustrate the limitations of analyses that, we argue, improperly restrict the decision context to the results of randomized trials and drug acquisition cost. We aim to inform questions surrounding the "value for money" associated with the use of human and long-acting analog insulins.

\section{MATERIALS AND METHODS}

\section{Literature Review}

The authors adopted a societal perspective by considering the direct and indirect costs associated with T2DM. The authors developed a prevalence-based budget impact assessment model that characterizes components of resource utilization (costs) associated with the periods surrounding insulin initiation, defined by the need for resources used in the 
management of T2DM. Evidence informing the budget impact model came from a literature search of PubMed using the keywords: "human insulin" OR "NPH" OR "glargine" OR "detemir" AND "cost" OR "resource utilization". Study titles and abstracts were first reviewed followed by complete manuscripts. Included studies were from 2006 onwards, an arbitrary cut-off to help ensure extracted data reflected contemporary clinical practice. The authors did not have access to a translation service and so only studies written in the English language were considered. Studies had to describe resource use (costs) associated with the use of human and analog insulin or either insulin alone. Data on total costs and cost components were extracted from each included study. Economic modeling studies were excluded as it was anticipated that the primary data contained in economic modeling studies could not be extracted readily or consistently.

Data from the reviewed studies was summarized for human insulin and long-acting analog insulins. The results for the human and analog insulins were stratified according to whether they were direct costs: hypoglycemiarelated, medications (diabetes or other), medical services (diabetes or other); or indirect costs.

\section{Analytical Approach}

Data from the included studies was summarized for each direct and indirect resource category associated with the management of T2DM and use of basal insulin. Data for total expenditure and diabetes-related medication expenditure were adjusted to 2011 values and standardized to British pounds sterling (GBP) in references to temporal changes in country exchange rates [19]. A quasi meta-analysis was undertaken whereby the point estimates from each study were weighted by the proportion of subjects in each insulin group. A full meta-analysis was not permitted, as the included studies did not consistently report variation around mean estimates. The data included in the analyses originated from several countries; to reflect the UK setting an adjustment was made in the budget impact calculations by scaling study estimates by the ratio of total healthcare expenditure as a percentage of output [gross domestic product (GDP)] in the UK to total healthcare expenditure as a percentage of GDP in the other country. Values obtained from published sources indicated the US spends $16.0 \%$ of its total GDP on healthcare, Germany $10.4 \%$, and the UK 8.4\% [20]. Point estimates for annual diabetes-related medication expenditure and total expenditure were obtained by multiplying annualized perperson estimates of expenditure by estimates of the prevalence of $\mathrm{T} 2 \mathrm{DM}$ in the UK, the proportion of the prevalent population using insulin therapy, and the proportion of people prescribed human and analog insulin.

\section{RESULTS}

\section{Literature Review}

The literature review identified 161 studies and a variety of resource utilization categories (Table 1). Of the reviewed studies nine were considered relevant (Tables 2, 3) [14, 21-28]. All studies were industry-sponsored. Details of the included studies including number of people, treatment setting, study year, study design and follow-up period, mean age, and primary objective, are reported in Table 4 [14, 21-28].

\section{Budget Impact Assessment}

In the budget impact assessment, total diabetesrelated medication expenditure per person was 
Table 1 Categories of resource utilization

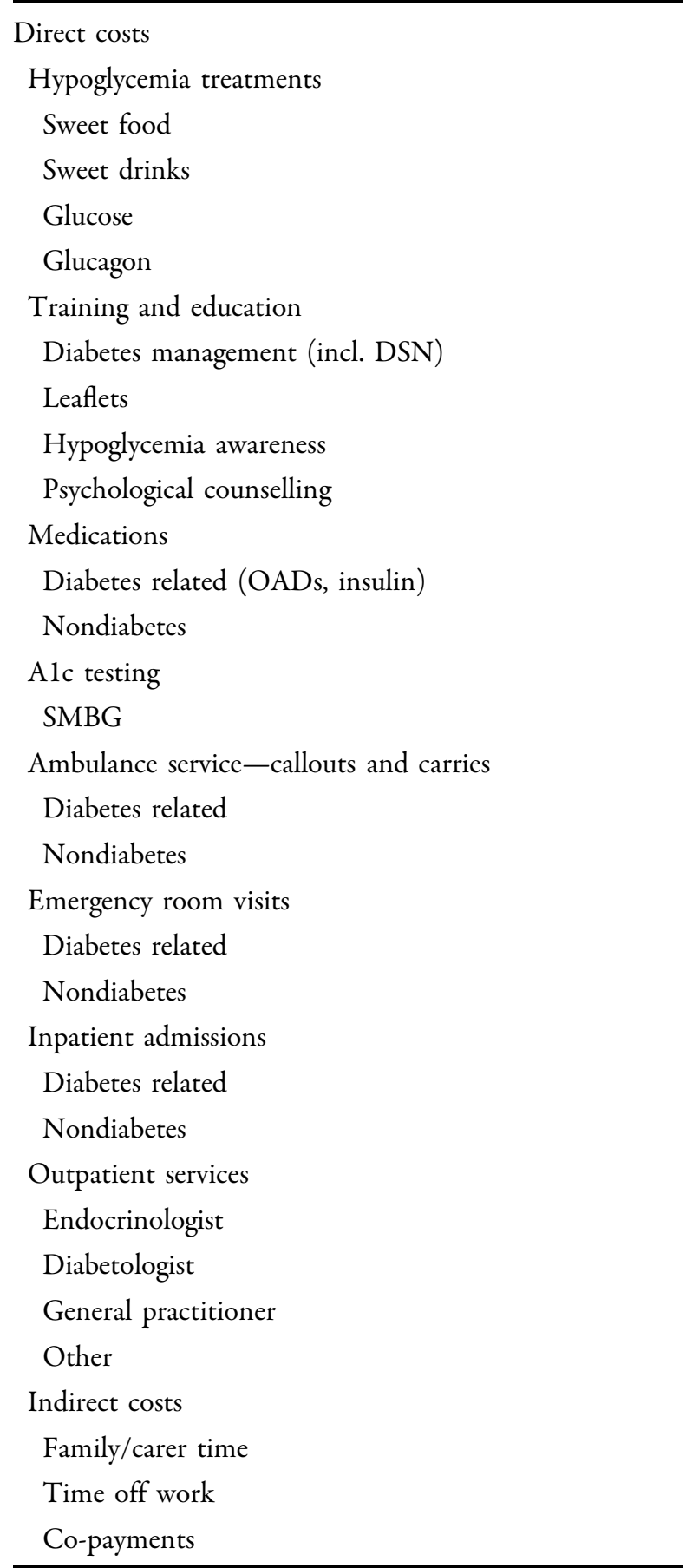

Alc glycated hemoglobin, $D S N$ diabetes specialist nurse, $O A D s$ oral antidiabetic drugs, $S M B G$ self-monitoring blood glucose

$15 \%$ lower each year with human insulin versus analog insulin. Once all relevant costs were factored into the analysis, the total annual expenditure associated with human insulin was $8 \%$ higher at an individual level compared to analog insulin, and this includes the cost of diabetes-related medications.

The authors estimate that for the UKprevalent population of T2DM, patients total and diabetes-related medication expenditure is $£ 3,901$ and $£ 397$ million, respectively, each year. The authors estimate that medication acquisition cost savings in the order of $£ 26$ million a year might be achieved if all analog insulin users converted to human insulin, but that any savings in medication acquisition cost would be consumed/offset by the estimated increase in overall treatment costs to individuals and the NHS of $£ 284$ million each year.

Across modeled scenarios whereby there is a positive utilization of each insulin type, a 10\% increased use of human insulin and a proportional decrease in the use of long-acting analog insulin would save the NHS around $£ 5$ million each year on drug acquisition cost, but the net overall cost to the NHS would increase by $£ 34$ million each year (Table 5 [1, 6, 8, 29], Fig. 1). For scenarios ranging from a $10 \%$ to $40 \%$ increased use of human insulin and an equivalent reduction in the use of analog insulins from current levels, this equates to a potential saving between $£ 5$ million and $£ 23$ million each year on drug acquisition cost, but the net overall cost to the NHS would increase by $£ 34$ million to $£ 136$ million each year.

\section{DISCUSSION}

In the management of T2DM a complicated picture arises when considering the relationship between overall clinical benefit (for example, glycemic control vs. hypoglycemia), treatment options (comparative effectiveness), and 
Table 2 Details of studies of human insulin (per patient per annum, 2011 GBP)

\begin{tabular}{|c|c|c|c|c|c|c|c|}
\hline & \multicolumn{7}{|l|}{ Study } \\
\hline & $\begin{array}{l}\text { Rhoads } \\
{[21]}\end{array}$ & $\begin{array}{l}\text { Lee } \\
{[22]^{\mathrm{a}}}\end{array}$ & $\begin{array}{l}\text { Schoffski } \\
{[23]^{\mathbf{b}}}\end{array}$ & $\begin{array}{l}\text { Brod } \\
{[14]^{c}}\end{array}$ & $\begin{array}{l}\text { Hammer et al. }[27] / \\
\text { Lammert et al. }[28]^{d}\end{array}$ & $\begin{array}{l}\text { Range } \\
(\mathrm{LL})^{\mathrm{e}}\end{array}$ & $\begin{array}{l}\text { Range } \\
(\text { UL) }\end{array}$ \\
\hline \multicolumn{8}{|l|}{ Diabetes-related costs } \\
\hline $\begin{array}{l}\text { Hypoglycemia } \\
\text { related }\end{array}$ & - & - & - & - & 1,069 & 1,069 & 1,069 \\
\hline $\begin{array}{l}\text { Medications/ } \\
\text { associated devices }\end{array}$ & - & 1,460 & 1,694 & - & - & 1,460 & 1,694 \\
\hline Medical costs & - & 1,617 & - & - & - & 1,617 & 1,617 \\
\hline Indirect costs & - & - & 10 & 1,186 & 35 & 10 & 1,186 \\
\hline Total & 5,493 & 3,076 & - & - & - & 3,076 & 5,493 \\
\hline \multicolumn{8}{|l|}{ Total costs } \\
\hline Medications & - & 5,875 & 1,949 & - & - & 1,949 & 5,875 \\
\hline Medical costs & - & 14,803 & 802 & - & - & 802 & 14,803 \\
\hline Indirect costs & - & - & 10 & 1,186 & - & 10 & 1,186 \\
\hline Total & 18,347 & 20,679 & 2,761 & - & - & 2,761 & 20,679 \\
\hline \multicolumn{8}{|c|}{$\begin{array}{l}\text { Weighted average across three treatment settings which were defined as the severe event being treated and managed by a } \\
\text { "family member/friend", "community healthcare worker" or "in hospital" } \\
\text { Historical exchange rates used for conversion [19] } \\
G B P \text { British pounds sterling, GDP gross domestic product, LL lower limit, OADs oral antidiabetic drugs, UL upper limit } \\
\text { a Values based on estimates post-insulin initiation, annualized } \\
\text { b Including insulins, OADs, blood glucose self-testing devices, pens and needles required for insulin administration } \\
\text { c Multi-country study of type } 1 \text { and } 2 \text { diabetes. Values refer to type } 2 \text { population only } \\
\text { d Multi-country study, UK data reported } \\
\text { e Data are point estimate (mean) values. Range refers to spread of mean values across included studies before adjustment for } \\
\text { variation in GDP per country or study size }\end{array}$} \\
\hline
\end{tabular}

consequent direct healthcare expenditure and indirect costs. Many clinical studiesrandomized and observational-have attempted to address the effectiveness and comparative effectiveness of technologies used in the management of T2DM [6, 30]. Certainly, many individual studies, mostly observational in nature, have often addressed narrow and disparate research questions about the financial costs associated with the management of T2DM. The aim of this study was to provide an understanding of the likely expenditure associated with T2DM and the use of different basal insulin products across patients, their families, health services, and society.

\section{Comparison to Other Studies}

In the UK it has been estimated that around $£ 3.5$ billion is spent on diabetes each year $[31,32]$. Looking across the various levels of a health service and more broadly into society, the authors estimate the total expenditure associated with T2DM to be $£ 3.9$ billion each year. Our analysis of human and analog insulins suggests that total annual diabetes-related medication expenditure is $£ 397$ million.

This analysis extends recent reports of the value for money relationship between human and analog insulins by delineating medication acquisition costs and total costs associated with 
Table 3 Details of studies of analog insulins (per patient per annum, 2011 GBP)

\begin{tabular}{|c|c|c|c|c|c|c|c|c|c|c|}
\hline & \multicolumn{10}{|l|}{ Study } \\
\hline & $\begin{array}{l}\text { Rhoads } \\
{[21]}\end{array}$ & $\begin{array}{l}\text { Lee } \\
{[22]^{a}}\end{array}$ & $\begin{array}{l}\text { Schoffski } \\
{[23]^{\mathbf{b}}}\end{array}$ & $\begin{array}{l}\text { Pscherer } \\
{[24]}\end{array}$ & $\begin{array}{l}\text { Bretzel } \\
{[25]}\end{array}$ & $\begin{array}{l}\text { Borah } \\
{[26]^{c}}\end{array}$ & $\begin{array}{l}\text { Brod } \\
{[14]^{d}}\end{array}$ & $\begin{array}{l}\text { Hammer } \\
\text { et al. }[27] / \\
\text { Lammert } \\
\text { et al. }[28]^{\text {e }}\end{array}$ & $\begin{array}{l}\text { Range } \\
(\mathbf{L L})^{\mathrm{f}}\end{array}$ & $\begin{array}{l}\text { Range } \\
(\text { UL })^{f}\end{array}$ \\
\hline \multicolumn{11}{|c|}{ Diabetes-related costs } \\
\hline $\begin{array}{l}\text { Hypoglycemia } \\
\text { related }\end{array}$ & - & - & - & - & - & - & - & 1,069 & 1,069 & 1,069 \\
\hline $\begin{array}{l}\text { Medications/ } \\
\text { associated } \\
\text { devices }\end{array}$ & - & 1,813 & 1,325 & 1,205 & 1,224 & 2,700 & - & - & 1,205 & 2,700 \\
\hline Medical costs & - & 831 & - & - & - & 3,196 & - & - & 831 & 3,196 \\
\hline Indirect costs & - & & 0 & - & - & - & 1,186 & 35 & 0 & 1,186 \\
\hline Total & 5,253 & 2,644 & - & - & - & - & - & - & 2,644 & 5,253 \\
\hline \multicolumn{11}{|l|}{ Total costs } \\
\hline Medications & - & 5,993 & 1,760 & - & - & 6,758 & - & - & 1,760 & 6,758 \\
\hline Medical costs & - & 11,813 & 739 & - & - & 8,052 & - & - & 739 & 11,813 \\
\hline Indirect costs & - & - & 0 & - & - & - & 1,186 & - & 0 & 1,186 \\
\hline Total & 16,576 & 17,806 & 2,499 & - & - & 15,854 & - & - & 2,499 & 17,806 \\
\hline
\end{tabular}

Weighted average across three treatment settings which were defined as the severe event being treated and managed by a "family member/friend", "community healthcare worker" or "in hospital"

Historical exchange rates used for conversion [19]

GBP British pounds sterling, GDP gross domestic product, $L L$ lower limit, $O A D s$ oral antidiabetic drugs, $U L$ upper limit

a Values based on estimates post insulin initiation, annualized

b Including insulins, OADs, blood glucose self-testing devices, pens and needles required for insulin administration

c 180 day follow-up period, annualized

d Multi-country study of type 1 and 2 diabetes. Values refer to type 2 population only

e Multi-country study, UK data reported

${ }^{f}$ Data are point estimate (mean) values. Range refers to spread of mean values across included studies before adjustment for variation in GDP per country or study size

human versus analog insulin use in the UK. This analysis suggests the maximum total cost saving if all users of analog insulin switched to human insulin would be around $£ 260$ million over a 10 -year period, less than half $(41 \%)$ of recent estimates suggesting total cost savings over the last 10 years might have been in the region of $£ 635$ million [8]. Furthermore, the authors show that any cost saving associated with the acquisition cost of the relatively less expensive human insulin is outweighed by the utilization of other healthcare resources and indirect costs.

\section{Limitations}

There are a number of limitations of this research that may impact the interpretation of the authors findings. Firstly, in restricting the literature search to recent studies in English and by excluding economic modeling studies there 


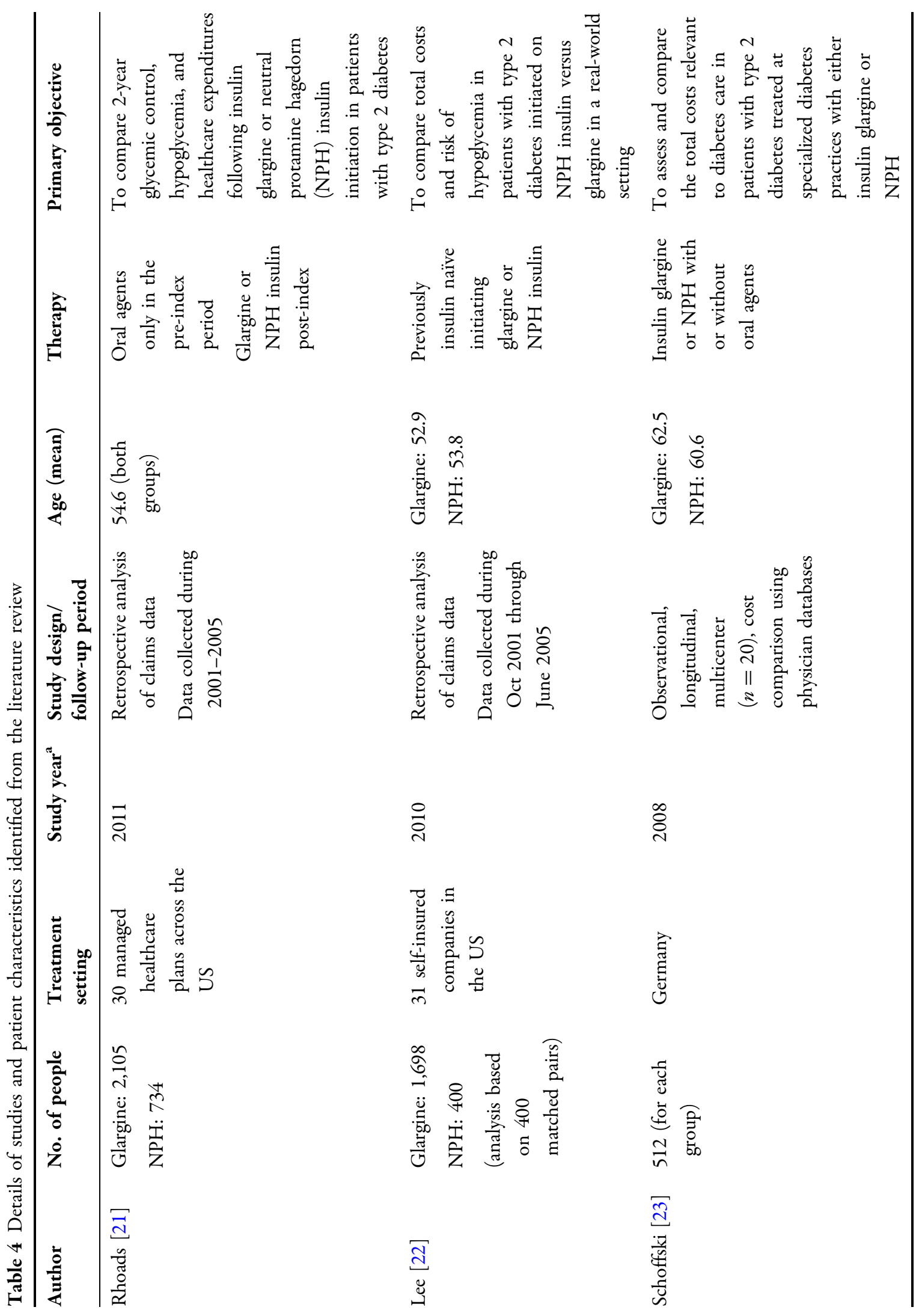




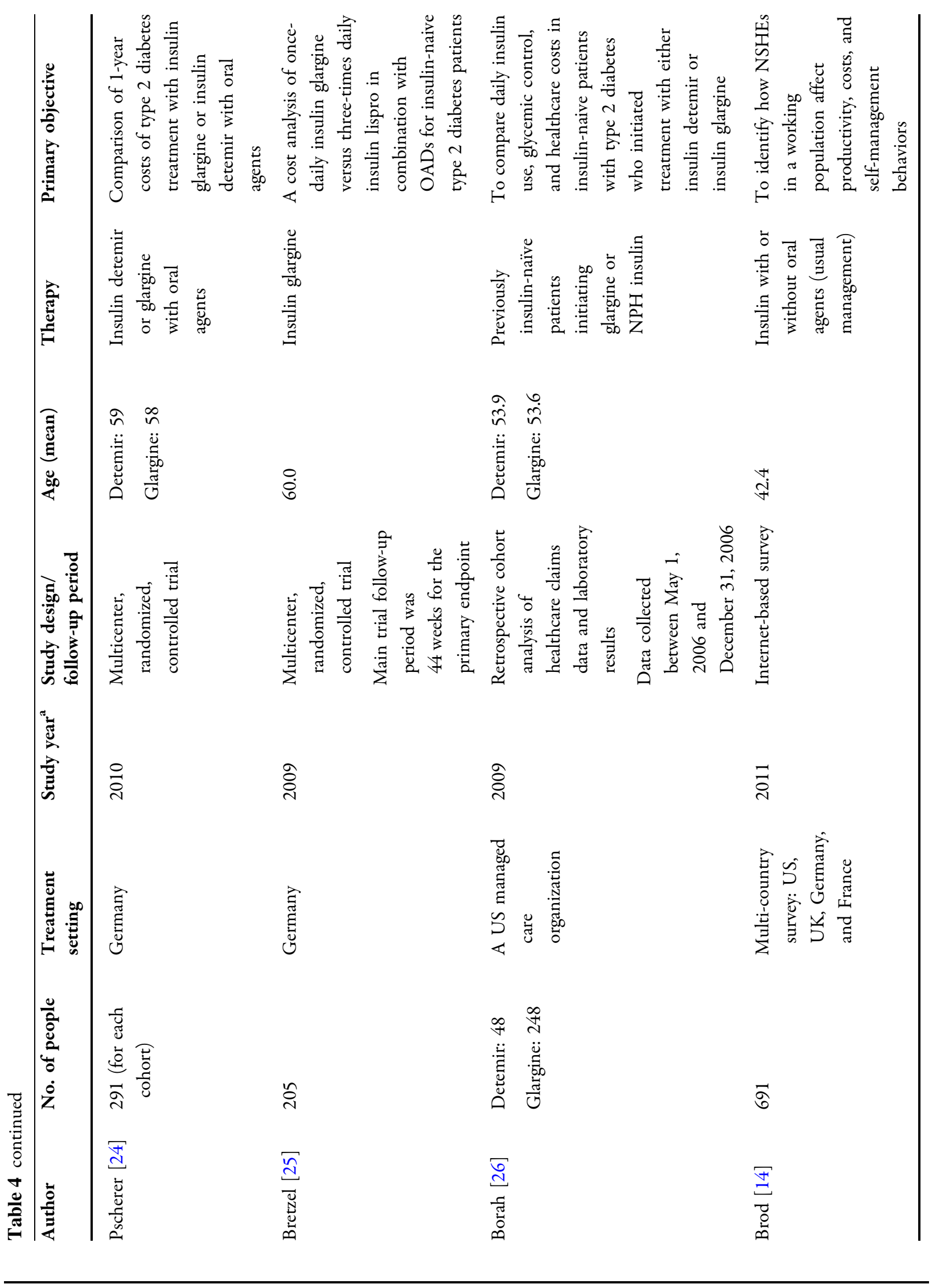




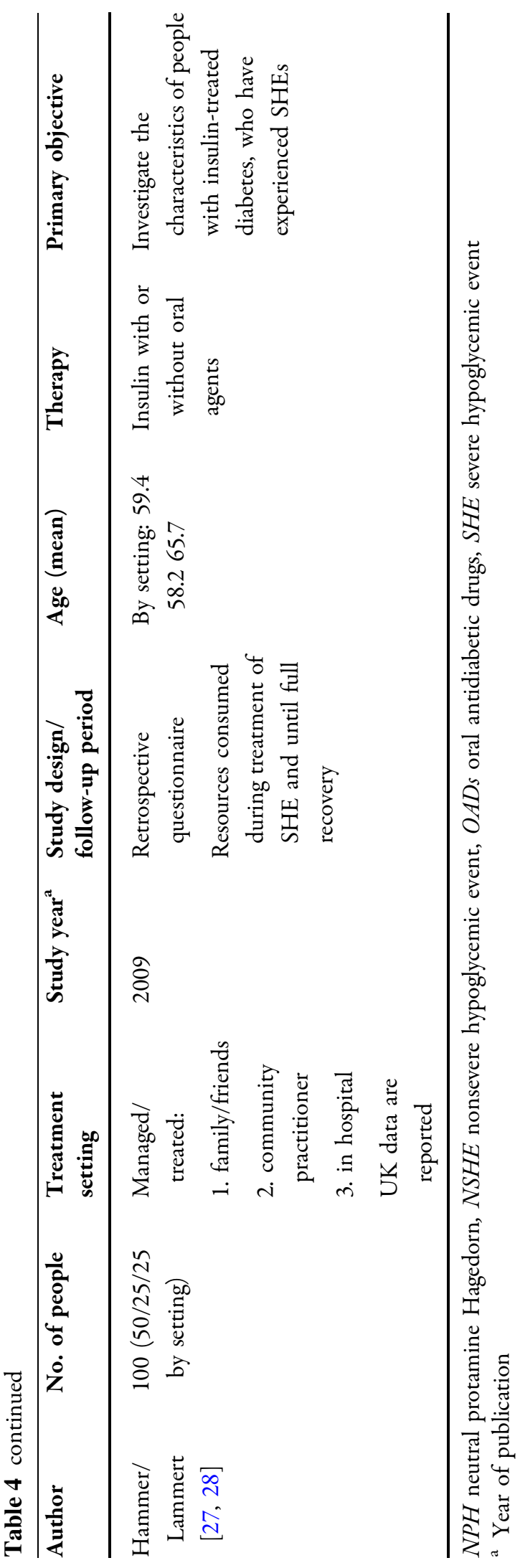

is a chance the authors have excluded potentially relevant studies from their estimations. Secondly, a full meta-analysis was not possible because the studies identified from the literature review did not consistently report variation around point estimates [only two of the nine studies reported estimates of variation, i.e., standard deviation (SD) or standard error (SE)]. Thus it was not possible to estimate the statistical heterogeneity between studies and therefore their similarity. In using a weighted average of point estimates, with study size as the weighting factor, we are able to quantify the cost implications associated with insulin use, which may be useful to other researchers and decision makers. The authors do stress, however, that caution should be exercised when interpreting their findings given that there may be important differences between the combined studies; the table of study details (Table 4) may be useful in addressing this limitation. Thirdly, the nature of study sponsorship (i.e., industry-sponsored research) may impact the results of an individual study and hence the synthesis of estimates across studies. One approach in addressing this type of bias is to exclude studies whose sponsorship may directly or indirectly affect study findings. The studies identified from the current literature review were all industry-sponsored. On this basis, the authors could not exclude industry-sponsored studies. The authors note this as a limitation of the available data and a potential source of bias in their study estimates.

\section{Cost Drivers}

Since the primary therapeutic advantage of the analog insulins relates to a reduction in hypoglycemia [33], potential cost drivers in this context include excess blood glucose monitoring costs [14], additional costs related 


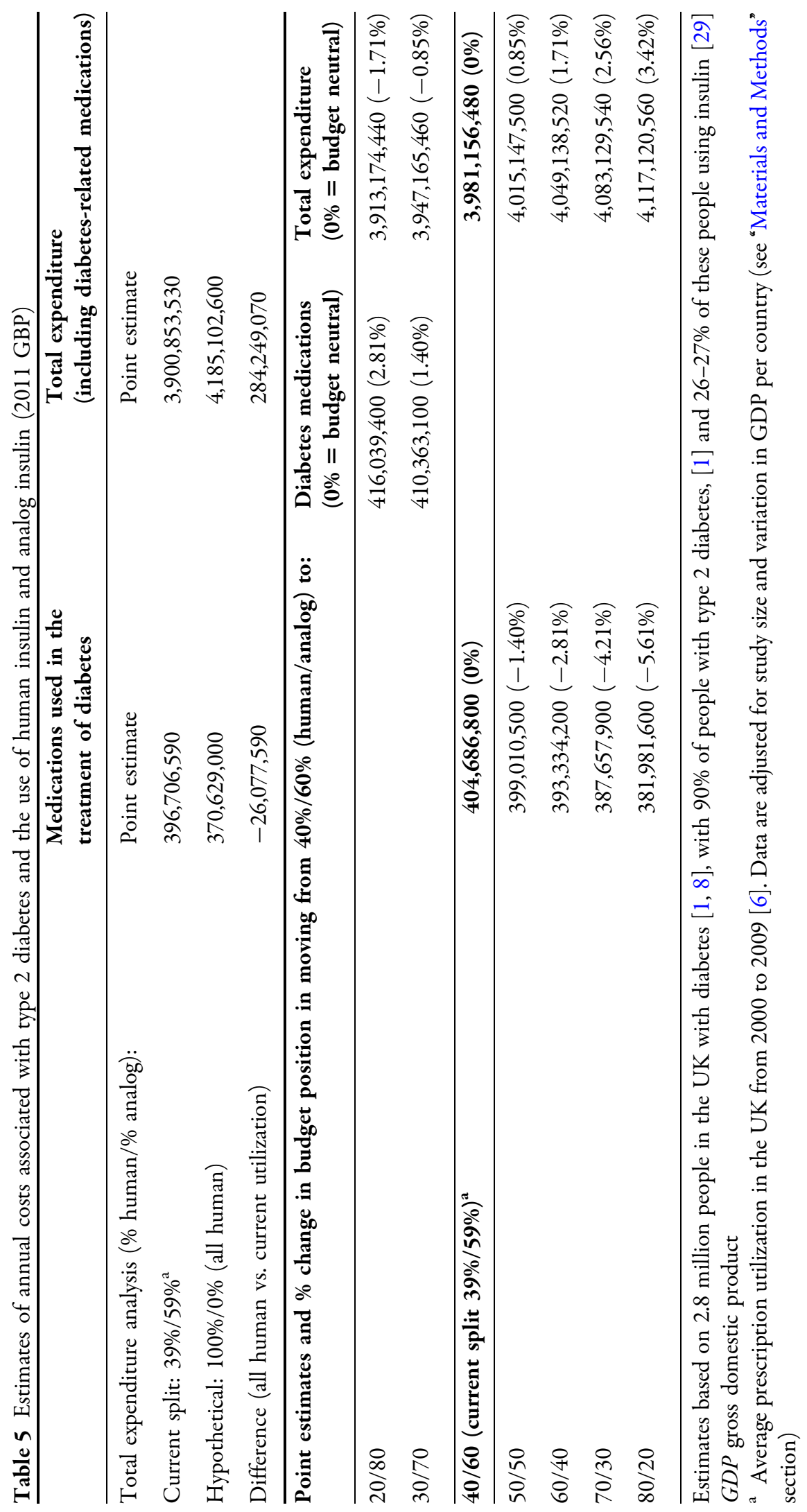




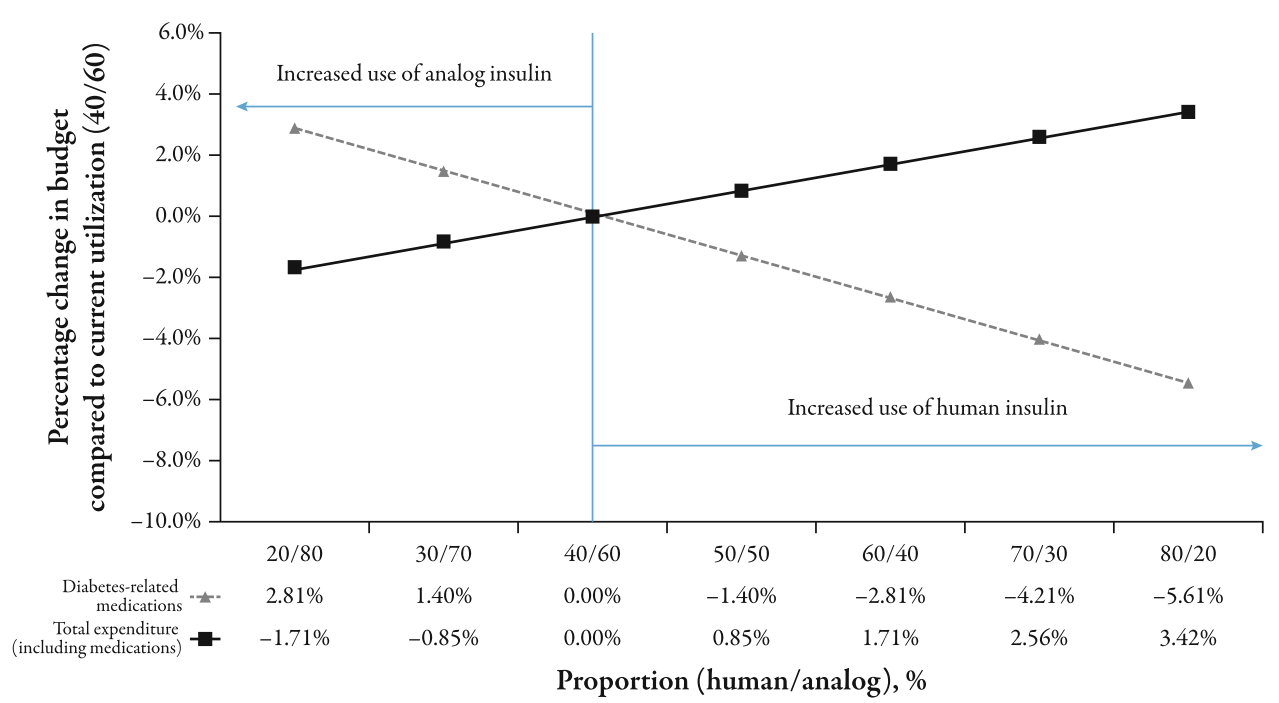

Fig. 1 Budget impact associated with increased use of human/analog insulin (2011 GBP)

to suboptimal insulin dosing and therapy nonadherence consequent upon hypoglycemia [34], and the costs associated with hypoglycemia-associated hospitalization [15, $35,36]$. In explaining why the more expensive long-acting insulin products can be cost saving in terms of total expenditure, the authors speculate to the association between the use of analog insulins and cost offsets associated with a reduction in hypoglycemic events and reduced frequency of injections from twice to once daily.

Hypoglycemia represents a major clinical barrier to achieving glycemic control in people with diabetes and has a major economic impact on overall healthcare spending. Over 30\% of people with T2DM treated with insulin experience symptomatic hypoglycemia [37], while data from recent mega trials evaluating the potential outcome benefit associated with intensification of glucose control has demonstrated an association between severe hypoglycemia and an increased risk of diabetes-related complications [38]. Furthermore, a recent retrospective observational analysis of $>860,000$ people with T2DM which examined the relationship between hypoglycemic events and acute cardiovascular events over a 2-year period demonstrated that after controlling for multiple confounders, patients with documented outpatient hypoglycemic events had a 79\% higher regression-adjusted odds [odds ratio 1.79; confidence interval (CI) 1.69-1.89] of acute cardiovascular events than patients without documented hypoglycemic events. In addition, those patients who experienced hypoglycemia incurred twofold greater health-related expenditure [15]. Further studies are required to confirm these findings.

Hypoglycemia results in significant resource utilization form a healthcare perspective. This concept is supported by the fact that hypoglycemia is the primary diagnosis resulting in 14,437 hospital admissions in the UK between 2009 and 2010, accounting for a total bed occupancy of 76,569 days [39].

Hypoglycemia also has a significant impact on the quality of life of people with diabetes as well as therapy adherence. Symptomatic hypoglycemia is associated with reduced therapy adherence, treatment satisfaction, and 
results in many people intentionally maintaining a state of hyperglycemia, with people with T2DM reducing their insulin dose $57.5 \%$ of the time following severe hypoglycemia, and $43.0 \%$ of the time following mild or moderate hypoglycemia [16, 17, 40, 41]. Indeed, fear of hypoglycemia in younger people with type 1 diabetes is greater than the fear of developing the later complications of diabetes [42]; it is possible that this relationship could carryover to people with T2DM.

A reduction in the frequency of nocturnal hypoglycemia is one the key advantages of the insulin analogs (insulin detemir and insulin glargine), compared to human insulin. This represents a major consideration when considering the value for money proposition of these insulin preparations since almost 50\% of all episodes of severe hypoglycemia occur at night during sleep [43]. Nocturnal hypoglycemia results in significant detrimental effects on mood and wellbeing the following day and has the greatest socioeconomic consequences from the perspective of reduced productivity and lost time at work, and represents a particular barrier to optimal insulin dose titration [14, 43, 44]. In addition, nocturnal hypoglycemia has been causally associated with acute sudden death [45], while recurrent nocturnal hypoglycemia is linked to the development of hypoglycemia unawareness, which in turn is associated with a higher rate of severe hypoglycemia [46].

Differences in rates of hypoglycemia between human and analog insulins were conflated in the results of the individual studies that informed our cost analysis. In the discussion the authors have only speculated to theoretically plausible clinical explanations of cost drivers. As such, we cannot directly attribute our expenditure estimates to different cost drivers. Instead we have used a linked evidence approach [47] to highlight the likely role of hypoglycemia as an overall cost driver and explanation for our key finding that human insulin is, on balance, likely to be more expensive than analog insulins.

\section{CONCLUSIONS}

It is difficult to gain a sense of the extent of expenditure made by individuals and governments in managing T2DM. The authors find that direct and indirect expenditure is significant. Diabetes-related medication expenditure is generally lower in users of human insulin compared to users of longacting analog insulin. Overall, though, the use of analog insulins was cost saving compared to human insulin. These productivity gains may be related to fewer hypoglycemic events.

The value for money of human insulin and analog insulins does not rest at medication acquisition costs alone. Governments and decision makers should consider that total healthcare expenditure will not necessarily decrease when decisions are based solely on the use of cheaper products. By factoring in the clinical benefits of insulin analogs in contrast to their higher costs, we estimate that a paradigm shift towards increased use of human insulin and decreased use of analog insulin would on average increase the net societal cost of managing insulin-treated patients with T2DM.

\section{ACKNOWLEDGMENTS}

Dr. Gordon is the guarantor for this article, and takes responsibility for the integrity of the work as a whole. This research was supported by an unrestricted educational grant from Sanofi, UK. 
Conflict of interest. JG, ME, PM, SB, and JV have received payment for lectures and consulting services to manufacturers of insulin products including Sanofi and Novo Nordisk. JG is an employee of HEOR Pty Ltd, and PM is an employee of HEOR Ltd.

Open Access. This article is distributed under the terms of the Creative Commons Attribution Noncommercial License which permits any noncommercial use, distribution, and reproduction in any medium, provided the original author(s) and the source are credited.

\section{REFERENCES}

1. World Health Organization 2011. Diabetes fact sheet Number 312. http://www.who.int/mediacentre/ factsheets/fs312/en/index.html. Accessed 5 Oct 2011.

2. Festa A, Williams K, D'Agostino R Jr, et al. The natural course of beta-cell function in nondiabetic and diabetic individuals: the insulin resistance atherosclerosis study. Diabetes. 2006;55:1114-20.

3. Wright A, Burden AC, Paisey RB, et al. Sulfonylurea inadequacy: efficacy of addition of insulin over 6 years in patients with type 2 diabetes in the U.K. Prospective Diabetes Study (UKPDS 57). Diabetes Care. 2002;25:330-6.

4. Nathan DM, Buse JB, Davidson MB, et al. Medical management of hyperglycemia in type 2 diabetes: A consensus algorithm for the initiation and adjustment of therapy. A consensus statement of the American Diabetes Association and the European Association for the Study of Diabetes. Diabetes Care. 2009;32:193-203.

5. Monesi L, Baviera M, Marzona I, et al. Prevalence, incidence and mortality of diagnosed diabetes: evidence from an Italian population-based study. Diabet Med. 2012;29:385-92.

6. Horvath K, Jeitler K, Berghold A, et al. Long-acting insulin analogues versus NPH insulin (human isophane insulin) for type 2 diabetes mellitus. Cochrane Database Syst Rev. 2007;2:CD005613.

7. QIPP. Cochrane quality and productivity topics. Long-acting insulin analogues versus NPH insulin (human isophane insulin) for type 2 diabetes mellitus. http://arms.evidence.nhs.uk/resources/ qipp/29481/attachment. Accessed 29 Dec 2012.

8. Holden SE, Poole CD, Morgan CL, et al. Evaluation of the incremental cost to the National Health Service of prescribing analogue insulin. BMJ Open. 2011;1:1-7.

9. Home PD, Fritsche A, Schinzel S, et al. Meta-analysis of individual patient data to assess the risk of hypoglycaemia in people with type 2 diabetes using $\mathrm{NPH}$ insulin or insulin glargine. Diabetes Obes Metab. 2010;12:772-9.

10. United Kingdom Prospective Diabetes Study (UKPDS) Group. Intensive blood-glucose control with sulphonylureas or insulin compared with conventional treatment and risk of complications in patients with type 2 diabetes (UKPDS 33). Lancet. 1998;352:837-53.

11. Patel A, MacMahon S, Chalmers J, et al. Intensive blood glucose control and vascular outcomes in patients with type 2 diabetes. $\mathrm{N}$ Engl J Med. 2008;358:2560-72.

12. Gerstein HC, Miller ME, Byington RP, The ADVANCE Collaborative Group, et al. The action to control cardiovascular risk in diabetes study group. Effects of intensive glucose lowering in type 2 diabetes. N Engl J Med. 2008;358: $2545-59$.

13. Heller SR, Choudhary P, Davies C, et al. Risk of hypoglycaemia in types 1 and 2 diabetes: effects of treatment modalities and their duration. Diabetologia. 2007;50:1140-7.

14. Brod M, Christensen T, Thomsen TL, et al. The impact of non-severe hypoglycemic events on work productivity and diabetes management. Value Health. 2011;14:665-71.

15. Johnston SS, Conner C, Aagren M, Smith DM, Bouchard J, Brett J. Evidence linking hypoglycemic events to an increased risk of acute cardiovascular events in patients with type 2 diabetes. Diabetes Care. 2011;34:1164-70.

16. Alvarez GF, Tofé PS, Krishnarajah G, et al. Hypoglycaemic symptoms, treatment satisfaction, adherence and their associations with glycaemic goal in patients with type 2 diabetes mellitus: findings from the Real-Life Effectiveness and Care Patterns of Diabetes Management (RECAP-DM) Study. Diabetes Obes Metab. 2008;10(Suppl. 1): 25-32.

17. Frier BM. How hypoglycaemia can affect the life of a person with diabetes. Diabetes Metab Res Rev. 2008;24:87-92. 
18. Jönsson B, CODE-2 Advisory Board. Revealing the cost of Type II diabetes in Europe. Diabetologia. 2002;45:S5-12.

19. Exchange rates-X-Rates. http://www.X-rates.com. Accessed 29 Dec 2012.

20. Organization for Economic Co-operation and Development (OECD). "OECD Health Data 2009". http://www.oecd.org/unitedstates/43800977.pdf. Accessed 14 Oct 2011.

21. Rhoads GG, Dain MP, Zhang Q, et al. Two-year glycaemic control and healthcare expenditures following initiation of insulin glargine versus neutral protamine Hagedorn insulin in type 2 diabetes. Diabetes Obes Metab. 2011;13:711-7.

22. Lee LJ, Yu AP, Johnson SJ, et al. Direct costs associated with initiating NPH insulin versus glargine in patients with type 2 diabetes: a retrospective database analysis. Diabetes Res Clin Pract. 2010;87:108-16.

23. Schöffski O, Breitscheidel L, Benter $\mathrm{U}$, et al. Resource utilisation and costs in patients with type 2 diabetes mellitus treated with insulin glargine or conventional basal insulin under realworld conditions in Germany: LIVE-SPP study. J Med Econ. 2008;11:695-712.

24. Pscherer S, Dietrich ES, Dippel FW, et al. Comparison of one-year costs of type 2 diabetes treatment with insulin glargine or insulin detemir in a basal supported oral therapy (BOT) in Germany. Int J Clin Pharmacol Ther. 2010;48: 129-37.

25. Bretzel RG, Dippel FW, Linn T, et al. Comparison of treatment costs in inadequately controlled type 2 diabetes in Germany based on the APOLLO trial with insulin glargine. J Med Econ. 2009;12:87-97.

26. Borah BJ, Darkow T, Bouchard J, et al. A comparison of insulin use, glycemic control, and health care costs with insulin detemir and insulin glargine in insulin-naive patients with type 2 diabetes. Clin Ther. 2009;31:623-31.

27. Hammer M, Lammert M, Mejías SM, et al. Costs of managing severe hypoglycaemia in three European countries. J Med Econ. 2009;12:281-90.

28. Lammert M, Hammer M, Frier BM. Management of severe hypoglycaemia: cultural similarities, differences and resource consumption in three European countries. J Med Econ. 2009;12:269-80.

29. Koro CE, Bowlin SJ, Bourgeois N, et al. Glycemic control from 1988 to 2000 among U.S. adults diagnosed with type 2 diabetes: a preliminary report. Diabetes Care. 2004;27:17-20.
30. Pollock RF, Erny-Albrecht KM, Kalsekar A, et al. Long-acting insulin analogs: a review of "realworld" effectiveness in patients with type 2 diabetes. Curr Diabetes Rev. 2011;7:61-74.

31. NHS Diabetes. Report number 46357 Diabetes in the NHS, 2007. Published by the National Diabetes Support Team on behalf a group of diabetes specialists in England. http://www.diabetes.nhs.uk/ document.php?o=318. Accessed 2 Oct 2011.

32. The NHS Information Centre, Prescribing and Primary Care Services. Prescribing for Diabetes in England: 2005/6 to 2010/11. http://www.ic.nhs.uk/ webfiles/publications/prescribing\%20diabetes\%202 00506\%20to\%20201011/Prescribing_for_Diabetes_ in_England_20056_to_201011.pdf. Accessed 4 Oct 2011.

33. Little S, Shaw J, Home P. Hypoglycemia rates with basal insulin analogs. Diabetes Technol Ther. 2011;13:S53-64.

34. Balkrishnan R, Rajagopalan R, Camacho FT, et al. Predictors of medication adherence and associated health care costs in an older population with type 2 diabetes mellitus: a longitudinal cohort study. Clin Ther. 2003;25:2958-71.

35. Johnston SS, Conner C, Aagren M, Ruiz K, Bouchard J. Association between hypoglycaemic events and fall-related fractures in Medicarecovered patients with type 2 diabetes. Diabetes Obes Metab. 2012;14:634-43.

36. Farmer AJ, Brockbank KJ, Keech ML, England EJ, Deakin CD. Incidence and costs of severe hypoglycaemia requiring attendance by the emergency medical services in South Central England. Diabet Med. 2012;29:1447-50.

37. Miller CD, Phillips LS, Ziemer DC, et al. Hypoglycemia in patients with type 2 diabetes mellitus. Arch Intern Med. 2001;161:1653-9.

38. The ADVANCE Collaborative Group. Severe hypoglycemia and risks of vascular events and death. N Engl J Med. 2010;363:1410-8.

39. HES online: Primary diagnosis-4 character table (2009/10). http://www.hesonline.nhs.uk/Ease/ servlet/ContentServer?siteID=1937\&categoryID=215. Accessed 9 Oct 2011.

40. Nakar S, Yitzhaki G, Rosenberg R, et al. Transition to insulin in type 2 diabetes: family physicians' misconception of patients' fears contributes to existing barriers. J Diabetes Complicat. 2007;21: 220-6.

41. Leiter LA, Yale J-F, Chiasson J-L, et al. Assessment of the impact of fear of hypoglycemic episodes on 
glycemic and hypoglycemia management. Can J Diabetes. 2005;29:186-92.

42. Nordfeldt S, Ludvigsson J. Fear and other disturbances of severe hypoglycaemia in children and adolescents with type 1 diabetes mellitus. J Pediatr Endocrinol. 2005;18:83-91.

43. Allen KV, Frier BM. Nocturnal hypoglycemia: clinical manifestations and therapeutic strategies toward prevention. Endocr Pract. 2003;9:530-43.

44. Yale JF. Nocturnal hypoglycemia in patients with insulin-treated diabetes. Diabetes Res Clin Pract. 2004;65:S41-6.
45. Tanenberg RJ, Newton CA, Drake AJ. Confirmation of hypoglycemia in the "dead-in-bed" syndrome, as captured by a retrospective continuous glucose monitoring system. Endocr Pract. 2010;16:244-8.

46. Henderson JN, Allen KV, Deary IJ, et al. Hypoglycaemia in insulin-treated type 2 diabetes: frequency, symptoms and impaired awareness. Diabet Med. 2003;20:1016-21.

47. Merlin T, Lehman S. The benefits and flaws of the Linked Evidence Approach (LEA) to assess diagnostic and screening tests [abstract]. Poster presented at: 7 th Annual Meeting, Health Technology Assessment international (HTAi); 6-9 June 2010, Dublin. 